\title{
O SERVIÇO SOCIAL BRASILEIRO NA ATUAL FASE DO CAPITALISMO: entre o conservadorismo e a resistência
}

\author{
Cristiana Costa Lima \\ Universidade Federal do Maranhão (UFMA)
}

\begin{abstract}
O SERVIÇO SOCIAL BRASILEIRO NA ATUAL FASE DO CAPITALISMO: entre o conservadorismo e a resistência Resumo: Problematização acerca da especificidade do Serviço Social no atual contexto histórico de desenvolvimento no Brasil. Apresenta a configuração do processo de constituição da região latino-americano na estratégia geral de ampliação do sistema do capital, reservando a essa região o papel de fornecedora dos bens primários necessários ao desenvolvimento dos países capitalistas centrais. Nesse cenário, evidencia que o Serviço Social surge e se consolida como profissão responsável por adequar à região a estratégia de controle social necessária para que o sistema se consolide. Reflete que, no Brasil, esse processo obteve forte resistência e até hegemonia na construção de um projeto político alternativo ao do capital, mas que, nos tempos atuais, enfrenta forte ataque do conservadorismo que, tendo feito parte da origem do Serviço Social brasileiro, retoma com força sua influência, agora sob outros parâmetros teóricos e formativos.
\end{abstract}

Palavras-chave: Capitalismo, Serviço Social, conservadorismo, resistência.

THE BRAZILIAN SOCIAL WORK ON CURRENT PHASE OF CAPITALISM: between conservatism and resistance Abstract: Questioning about the specificity of Social Work in the current historical context of development in Brazil. It displays the configuration of the maintenance process of the Latin American region into the strategy of expansion of the capital system, reserving that the role of supplier of primary goods needed for the development of the central capitalist countries. In this scenario, shows that social work emerges and consolidates as a responsible profession of adjusting to the region social control strategy required for the system to be consolidated. It reflects that in Brazil, this process received strong resistance and even hegemony in the construction of an alternative political project to the capital, but, nowadays, it faces strong attack of conservatism that, having been part of the origin of the Brazilian Social Service resumes strongly influence, now under other theoretical and training parameters.

Key words: Capitalism, Social Work, conservatism, resistance. 


\section{INTRODUÇÃO}

O processo histórico de inserção dos países latino-americanos na estrutura produtiva capitalista mundial evidencia a relação dependente dos estados nacionais da região às estratégias dos organismos internacionais, como o Banco Mundial (BM), Organização Mundial do Comércio (OMC), Fundo Monetário Internacional (FMI), etc. Sobretudo o BM

[...] tem a atribuição de um grande intelectual orgânico dos interesses representados pelo G-7, atuando como um 'organizador' das políticas dos países em desenvolvimento. (LEHER, 1998, p. 9, grifo do autor).

Organismos que operam no permanente equacionamento das posições a serem ocupadas na dinâmica mundial do sistema, no qual, como aponta Mészáros (1979, p. 54),

[...] crescimento e expansão são necessidades imanentes do sistema de produção e, quando os limites locais são atingidos, não resta outra saída a não ser reajustar violentamente a relação dominante de forças.

Ajustes na perspectiva desigual e combinada da expansão do modo de produção.

No Brasil, onde se

[...] reconhece a necessidade de políticas de redução das desigualdades, porém não faz referência ou dá pouca ênfase às reformas que afetam a estrutura tributária e a distribuição da riqueza. (GONÇALVES, 2012, p, 661).

Temos "[...] mais uma versão do modelo de liberalismo enraizado [...]" (GONÇALVES, 2012, p. $662)$.

\section{Claramente}

[...] um fenômeno recente e localizado, indissociável das particularidades da economia e da política brasileiras na segunda metade dos anos 2000. (SAMPAIO JR., 2012, p. 678).

Um desenvolvimento apenas como simulacro.

Esse processo ocorre com a presença do Estado, sob a ideologia do desenvolvimento, desta feita travestida de novo-desenvolvimentismo, que em nada se assemelha ao velho desenvolvimentismo ocorrido nos anos 1930-1980.

No caso específico do Serviço Social na América Latina sob as profundas transformações impostas pela lógica do capital, verifica-se um redimensionamento e criação de novos espaços do exercício profissional, fazendo emergir inéditas requisições de demandas a esse profissional, novas habilidades, competências e atribuições que influenciam diretamente a ação e a formação do profissional.

2 O SERVIÇO SOCIAL NO BRASIL: entre O conservadorismo e a resistência

O surgimento e a institucionalização do Serviço Social na América Latina inter-relacionamse diretamente com a dinâmica econômica, religiosa, social, política e do movimento das classes sociais, sobretudo a partir da década de 1930. O Serviço Social não pode ser bem compreendido descolado do contexto que o gera, o que implica desvendar sua real função no movimento concreto da vida social. Com isso, entendemos que o Serviço Social surge como estratégia de controle social ${ }^{1}$ no conjunto das determinações que são geradas pela sociedade capitalista. O Serviço Social não expressa

\section{[...] mera derivação de exigências e demandas postas pelo agravamento da questão social, no início deste século, nem uma consequência lógica de um processo cumulativo no campo da racionalização da filantropia em bases teórico-científicas. Traduz-se, então, como síntese de um conjunto de determinações históricas que reflete o tratamento dado à referida questão pelas classes sociais, a partir de processos particulares corporificados em mediações estabelecidas entre a sociedade civil e o Estado no enfrentamento da mesma questão. (ABREU, 2002, p. 41).}

Para garantir a defesa da ordem capitalista instaurada, a burguesia viu-se compelida a estabelecer estratégias de assistência às camadas pauperizadas da população. Esse processo, no entanto, possui raízes anteriores, situadas no movimento das classes sociais na Europa do século XIX, sob ampla interferência das ideias da Igreja Católica. Temos precisamente no ano de 1848 o marco da disputa entre o avanço das ideias liberais e nacionalistas pela consolidação da burguesia no poder e a entrada do proletariado industrial na arena política. Foi o ano de intensas mobilizações, por parte do proletário urbano industrial como força política organizada, que resultaram em diversos levantes contra o projeto de restabelecer o Antigo Regime monárquico - movimento histórico que ficaria conhecido como a Primavera dos Povos. Esse é um dos elementos fundamentais para compreender a base material e concreta da criação de profissões, a exemplo do Serviço Social - embora não se restrinja a ela -, especificamente voltada para mecanismos 
de racionalização da assistência e aos processos decorrentes de agudização da pobreza (LOPES, 2001).

Como aponta Lopes (2001), a profissionalização do Serviço Social na América Latina é um fenômeno do século XX, emergindo sob o signo do conservadorismo e da reação, pósRevolução Russa (1917), cujas forças hegemônicas do capitalismo e da Igreja Católica passaram a agir e a se relacionar com as massas para conter a ameaça do comunismo em todo o globo.

O modelo de desenvolvimento oligárquico dependente implementado na América Latina sustentou-se em dois eixos, como nos expõe Cueva (1990, p. 79, tradução nossa): (1) "[...] o capitalismo não se implanta mediante uma revolução democrático-burguesa que destrói radicalmente os fundamentos da antiga ordem" e (2) "[...] nasce e se desenvolve subordinado à fase imperialista do capitalismo".

O desenvolvimento capitalista latinoamericano é fruto dessa lógica, expressa na máxima lampedusiana (1974), registrada em O Leopardo, segundo a qual "[...] se quisermos que tudo fique como está é preciso que tudo mude [...]", subordinando os países de maneira dependente à expansão do capitalismo mundial. Processo que é resultante da constituição da burguesia na América Latina, que "[...] nasce aqui confundida e entrelaçada em sua origem e sua estrutura com a aristocracia latifundiária”. (CUEVA, 1990, p. 85, tradução nossa).

Situamos, então, o surgimento do Serviço Social no marco do capitalismo monopolista ${ }^{2}$. Essa fase do capitalismo é marcada pela agudização das contradições da ordem burguesa a partir da acentuação da alienação, da exploração dos trabalhadores, aumento dos lucros capitalistas pelo aumento do exército industrial de reserva. $O$ capitalismo monopolista altera significativamente a dinâmica da sociedade burguesa, como destaca Paulo Netto (1996).

Nesse turbilhão de transformações, os assistentes sociais eram requisitados para organizar o consenso e a adesão das classes subalternas à nova ordem do capital. Sua intervenção profissional é vinculada ao conjunto de mediações que caracterizam a articulação orgânica entre a produção material e a reprodução física e subjetiva da força de trabalho (ABREU, 2002).

Em síntese: o Serviço Social tem sua origem sob o âmbito da estratégia de controle social do capital, sendo criado como um instrumento para o enfrentamento da questão social, com a mediação do Estado e da Igreja para atenuar o conflito capital e trabalho. Coube ao Serviço Social materializar essa estratégia de controle social que se deu sob dois movimentos complementares, como nos apresenta Abreu (2002, p. 58):
1) A profissão inscreve-se no conjunto dos processos político-culturais articulados, assimilados e criados pela burguesia industrial americana, constituindo uma via de difusão e expansão dos princípios tayloristas, como padrão de racionalidade inerente ao movimento de reprodução e acumulação do capital; em que o Serviço Social:

1.1) Cumpre o papel de formador dos quadros da tecnocracia fabril e da burocracia estatal dentro do campo de influência do taylorismo e;

1.2) Tem protagonismo na difusão desse padrão taylorista junto ao disciplinamento das relações sociais, racionalizando e tecnificando a assistência social;

2) A profissão converte-se numa das frentes mobilizadas pela Igreja Católica para a recuperação moral do operariado, face às influências consideras maléficas dos ideais socialistas e do liberalismo econômico (ABREU, 2002).

O projeto profissional do assistente social foi perpassado, portanto, por uma visão harmoniosa e equilibrada dessa sociedade. Os documentos de Araxá (1967) e Teresópolis (1970) são referências significativas desse projeto profissional. Eles se constituem no marco da teorização do Serviço Social brasileiro que influenciou fortemente outras escolas latino-americanas. Resultaram de seminários (Araxá, em 1967; Teresópolis, em 1970) convocados pelo Centro Brasileiro de Cooperação e Intercâmbio de Serviços Sociais (CBCISS), cujos objetivos eram refletir sobre a teorização do Serviço Social. Em continuidade às reflexões de Araxá, o documento de Teresópolis equivale

[...] à plena adequação do Serviço Social à ambiência própria da "modernização conservadora" conduzida pelo Estado ditatorial em benefício do grande capital e às características sócioeconômicas e político-institucionais do desenvolvimento capitalista ocorrente em seus limites. (PAULO NETTO, 2006a, p. 193, grifo do autor).

Porém, a década de 1960 é marcada também pela forte crise do modelo desenvolvimentista que não conseguiu conter inflação, altos custos de vida, acentuada concentração de renda e sua má distribuição, crescente endividamento externo, aumento da exploração da força de trabalho, ocasionando aumento da pobreza e da miséria. Países como Argentina, Brasil, Chile, Colômbia, Equador, Honduras, México, Uruguai e Venezuela foram fortemente atingidos pela crise. A esse respeito, destaca Cueva (1990, p. 199, tradução nossa, grifos do autor), 
No começo dos anos sessenta, nem mesmo os mais fervorosos defensores do capitalismo podiam se gabar do curso que este havia seguido na América Latina. Todos sabiam que o projeto de desenvolvimento nacional autônomo estava em falência e que o capital imperialista era o dono e senhor de nossa economia; o estado semicolonial foi reconhecido inclusive oficialmente, sendo designado com o eufemismo "situação de dependência", que logo se difundiria amplamente. $E$ também não se podia negar que se havia iniciado um processo de pauperização absoluta das massas, reconhecido através da fórmula de "redistribuição regressiva da renda".

Cenário que propicia um substancial avanço na reflexão dos fundamentos teóricos-metodológicos do Serviço Social, agora sob influência do marxismo.

O Serviço Social na América Latina inicia o questionamento de suas bases de legitimação sob uma era de extremos, como definiu Hobsbawn (2003), em que a opção por um projeto de sociedade tornara-se uma escolha concreta a ser definida ante o mundo bipolar instaurado no planeta. Se os séculos XVIII e XIX foram os séculos das revoluções burguesas por toda a Europa, o século $X X$ trouxe a palco as revoluções lideradas pelo Trabalho no Mundo e, especialmente, nos países da América Latina e Caribe, assumindo um caráter de rompimento com a dominação imperialista dos Estados Unidos e com a submissão das massas populares às classes dominantes. A vitória da Revolução Cubana, em 1959, exerceu essa profunda influência nos movimentos e nas lutas sociais. Ela significou um divisor de águas na América Latina e modificou a qualidade da história e da consciência histórica dos sujeitos.

Começa então a ser gestado o Movimento de Reconceituação do Serviço Social que se configura através da crítica e da ação de setores expressivos dos profissionais, que encontraram nos movimentos progressistas e revolucionários da década de 1950 e 1960 condições de propor e avançar na construção de um projeto profissional alternativo de Serviço Social (LOPES, 2001).

Destarte, como analisa José Paulo Netto (2006b), o Movimento de Reconceituação brasileiro não representou uma homogeneidade de pensamento no interior da profissão. Há uma explicitação de correntes e tendências: a perspectiva modernizadora; a reatualização do conservadorismo ${ }^{3}$ através de uma nova roupagem, utilizando-se dos recursos à fenomenologia; e, por fim, o projeto de intenção de ruptura (PAULO NETTO, 2006b).

O Serviço Social passou por um processo de amadurecimento, alargamento e expansão jamais visto antes. O mercado de trabalho se amplia e a profissão torna-se cada vez mais laica.É um momento de crítica às práticas profissionais tradicionais, de engajamento de profissionais nos movimentos de esquerda nesse país.

O Movimento de Reconceituação, um marco na história do Serviço Social no continente, teve início na década de 1960, em países como Brasil, Uruguai, Argentina, Chile e, posteriormente, difundindo-se por toda a América Latina. É nessa década que as bases conservadoras que sustentam a profissão entram em crise. Isso ocorre impulsionado pelas mudanças sociais, políticas, econômicas e culturais na América Latina. Como interpreta Alayón (2007, p. 12, tradução nossa, grifo do autor),

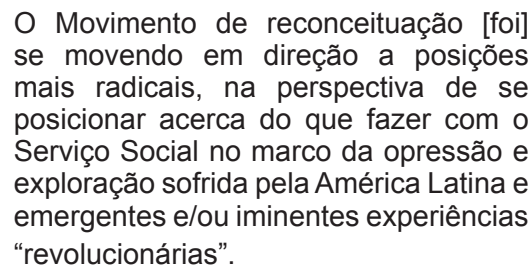

Contudo, é importante reafirmar que as modificações ocorridas no Serviço Social durante essas décadas são marcadas pelas profundas transformações da sociedade e pelo avanço das lutas das classes e do movimento social e popular que "[...] colocava a questão social frente ao capital e a questão nacional frente ao imperialismo na ordem do dia." (LOPES, 2001, p. 56).

A organização política da categoria, vinculada à luta dos trabalhadores, ganha importância no processo de ruptura com o Serviço Social tradicional. Portanto, a tarefa de construção de um Serviço Social alternativo é uma tarefa coletiva que supõe a consciência sobre a função imposta pelo capital à profissão, bem como sobre as possibilidades históricas de destruição da velha sociedade e construção de uma nova como tarefa coletiva dos trabalhadores organizados politicamente sob diferentes formas (LOPES, 2001).

Diante do exposto, fica claro que as transformações pelas quais o Serviço Social na região passava, e passa, não podem ser consideradas como um patrimônio exclusivo da profissão. O processo de formação da consciência dos assistentes sociais acompanha o movimento histórico da sociedade, como produto das classes em luta, refletindo na disputa de projetos de profissão a serem implementados. Essa disputa de tendências teóricas e políticas perpassou, e ainda perpassa, a profissão em todos os seus eixos, seja o interventivo, o da formação profissional ou o organizativo. Portanto, em conformidade com Lopes (2001, p. 65),

[...] desde sua deflagração, o Movimento de Reconceituação avança e se adensa, também sob o impulso da crítica e da luta política em seu interior, relacionando-se de várias maneiras com os processos de luta política travados na sociedade 
(mundial, no continente e no interior de cada país) na qual o movimento do Serviço Social é apenas um elemento.

Fruto de correntes contraditórias em seu próprio interior - de um lado a proposta de modernização conservadora e, do outro, a de um projeto alternativo de sociedade -, o Movimento de Reconceituação expressou as condições de seu tempo e de lugares. A questão que se coloca é: em que medida mantém-se como projeto profissional?

A década dos anos 1990, o período da imensa vitória ideológica do neoliberalismo, ainda que de derrota no plano econômico, como avaliou Perry Anderson, rebateu duramente sobre o projeto profissional do Serviço Social. Não a ponto de eliminá-lo ou de levar a cabo sua exaustão, mas de colocá-lo em profundo isolamento ideológico e político, posto que espraiou-se na sociedade a concepção conservadora pós-moderna de atomização do indivíduo e afirmação das bases mercadológicas das diversas instâncias da vida.

Sob esse contexto, o projeto alternativo do Serviço Social tem pautado sua resistência em: políticas educacionais implementadas no País que impulsionam um ensino aligeirado, tecnicista, pragmático e desvinculado de qualquer reflexão no horizonte emancipador; uma ampla gama de possibilidades profissionais no mercado de trabalho em torno da temática da assistência social, mormente as políticas, também ditadas pelos organismos internacionais, de redução da miséria e da pobreza, que, mesmo implementadas por governos progressistas que emergiram no continente latino, em boa medida não romperam com a perspectiva assistencialista e focalizada dessas políticas, mas que, ao se constituírem em espaço de atuação dos assistentes sociais, acabaram por delimitar o espaço de reflexão da categoria às demandas trazidas por essas políticas. É sob essa nova maré que rema contrariamente o projeto profissional do Serviço Social.

Poderíamos apontar pelo menos duas perspectivas para o Serviço Social na atualidade: uma reatualização do conservadorismo vinculadas à ajuda psicossocial individualizada e da participação para o ajustamento; e outra que, com base no Movimento de Reconceituação, aponta para a construção da emancipação humana. Contudo, como bem destaca Abreu (2002), essa perspectiva encontra-se entre o horizonte dos compromissos profissionais com as lutas das classes subalternas no âmbito dos direitos sociais, civis e políticos, portanto nos limites das conquistas do Estado de Bem-Estar Social, e o horizonte que ultrapassa o limite das conquistas das classes trabalhadoras no sentido de construção de uma nova sociabilidade - a socialista.

A primeira vem se delineando desde o período do governo FHC (1995-2002) onde a política social inicia com a ênfase na dimensão da solidariedade, nos programas sociais, ainda que dispersos em vários ministérios, enfatizando a focalização, no governo Luís Inácio Lula da Silva (2003-2010), essas características aprofundam-se, embora permutando a dimensão da solidariedade pelo chamamento ao combate à fome. Mas, em ambos os governos, abandonando-se a dimensão da universalidade e da garantia do direito ao trabalho.

No governo Lula, o enfrentamento da questão social e, em particular, sua expressão mais cruel, a pobreza, sustenta-se naquilo que foi um dos núcleos centrais da gênese do movimento crítico que fundou o projeto ético-político com uma alternativa ao projeto tradicional da profissão: a luta contra o assistencialismo (LOPES, 2009).

O assistencialismo sob a era lulista também reforça o crescimento, entre os profissionais do Serviço Social, da

[...] perspectiva da luta pela assistência como direito, cuja centralidade pode obstruir a perspectiva da luta fundamental na sociedade capitalista que é o direito ao trabalho. [Reafirmamos]. (ABREU, LOPES, 2006, p. 9).

Mesmo sob o propagandeado avanço da política social brasileira pelo Iulismo, o que temos no Brasil é tal e qual o que é permitido aos países dependentes desenvolverem: políticas sociais focalistas, setorizadas, fragmentadas, autonomizadas, formalistas, abstraídas de conteúdos (político-econômicos) concretos, cuja natureza compensatória, caráter fragmentado e abstrato expressam o seu limite de não objetivar romper e, de fato, não rompem com a lógica capitalista (GUERRA, 2009).

Assim,

[...] acentua-se a tendência neoconservadora, focalista, controlista, localista, de abordagem microscópica das questões sociais, transformadas em problemas ético-morais. (GUERRA, 2009, p. 16).

Ora, se considerarmos que o conservadorismo foi um elemento constitutivo da trajetória do Serviço Social, sua emergência no período atual, de pouca mobilização e residual resistência à cultura neoliberal, é mais que um dado conjuntural. É um fato o qual as forças do projeto ético-político do Serviço Social precisam anotar com a devida importância. Embora ainda pouco influente, mas já em significativo crescimento nas escolas, essa corrente também contribui para o ressurgimento do conservadorismo no Serviço Social. O que leva a um embate em diversas especificidades do projeto ético-político: no plano ético - o distanciamento de uma ética intrínseca à configuração do ser social para uma ética particularista, conforme a visão 
teocêntrica do mundo dada pela opção religiosa; no plano ideológico - fortalecimento da perspectiva do abandono da utopia emancipatória; no plano político - o crescimento de articulações que caem no encanto da pauta objetiva da realidade profissional acerca das condições de trabalho e salariais, mas crescentemente de cunho eminentemente corporativista; no plano prático-social - pelo qual cresce a dicotomização entre prática e teoria, distanciando a realidade da elaboração teóricometodológica, o que leva a duas consequências, como corretamente observa Santos (2007, p. 111):

[...] o conservadorismo agora tem como pré-requisito para se fortalecer a descredibilização da vertente críticodialética e o faz, do ponto de vista teórico, incorporando as críticas pósmodernas ao marxismo; e do ponto de vista ideopolítico, investindo na deslegitimação do projeto-ético-políticoprofissional.

Desses elementos, resulta o seguinte cenário: o projeto ético-político do Serviço Social e sua hegemonia no interior da formação profissional está sob duplo ataque: de um lado, pelo conservadorismo metamorfoseado pelo pensamento pós-moderno; e do outro, pelos setores que aderiram ao neoliberalismo em seu viés novo-desenvolvimentista. No primeiro, a tese de que o projeto ético-político não dá conta da prática profissional; no segundo, a flexibilização dos princípios que sustentam o projeto ético-político (BRAZ, 2004). Ambos, confluindo para o fortalecimento da avalanche conservadora e direitização da sociedade capitalista que tem hegemonizado a sociedade brasileira (ABREU; LOPES, 2006).

\section{CONCLUSÃO}

Nesse contexto, a hegemonia do projeto ético-político está sob inédito e forte combate, mas tem reagido com a fortíssima resistência que o tempo requer. Nesse embate, o enfrentamento prioritário deve ser à indiscriminada expansão do ensino privado e a distância, pois é por eles que se dará o tensionamento pela reconfiguração do Serviço Social e a deslegitimação de seu projeto ético-político pela emancipação humana. Sem, porém, deixar de atentar ao desmonte e à mercantilização que vem sendo impostos ao ensino público sob as políticas educacionais preconizadas pelos organismos internacionais.

\section{REFERÊNCIAS}

ABREU, M. M. Serviço Social e organização da cultura: perfis pedagógicos da prática profissional. São Paulo: Cortez, 2002.
; LOPES, J. B. L. A formação profissional do assistente social no contexto da atual reestruturação do capital: respostas e questões das diretrizes curriculares no Brasil. In: CONGRESSO MUNDIAL DE ESCOLAS DE SERVIÇO SOCIAL, 33., 2006, Santiago de Chile. Anais... Santiago de Chile, 2006.

ALAYÓN, N. El Movimiento de reconceptualización: uma mirada crítica. In: SANTOS, M. J. C. Trabajo social latinoamericano: a 40 años de la reconceptualización. 2. ed. aum. Buenos Aires: Espacio Editorial, 2007.

BRAZ, M. A hegemonia em Xeque. Projeto éticopolítico do Serviço Social e seus elementos constitutivos. Revista Inscrita, Brasília, DF, n. 10, p. 5-10, 2004.

CUEVA, A. El desarrollo del capitalismo em América Latina. México: Siglo Veintiuno Editores, 1990.

GONÇALVES, R. Novo desenvolvimentismo e liberalismo enraizado. Serviço Social e Sociedade, São Paulo, v. 112, p. 637-671, out./dez. 2012.

GUERRA, Y. A Crise Contemporânea e os impactos no Serviço Social. In: CONGRESO LATINO AMERICANO DE ESCUELAS DE TRABAJO SOCIAL, 16., 2009, Costa Rica. Anais. Costa Rica: Universidad de Costa Rica, 2009. Disponível em:<www.ts.ucr.ac.cr>. Acesso em: 28 nov. 2013.

HOBSBAWM, E. Era dos extremos: o breve século XX (1914-1991). São Paulo: Companhia das Letras, 2003.

LEHER, R. Da ideologia do desenvolvimento à ideologia da globalização: a educação como estratégia do Banco Mundial para o "alívio" da pobreza. 1998. 297 f. Tese (Doutorado em Educação) - Faculdade de Educação, Universidade de São Paulo, São Paulo, 1998.

LOPES, J. B. O Serviço Social na América Latina: nas malhas da modernização conservadora e do projeto alternativo de sociedade. 2001. Tese (Doutorado em Serviço Social) - Pontifícia Universidade Católica de São Paulo, São Paulo, 2001.

MÉSZÁROS, I. Ontologia do ser social: os princípios ontológicos fundamentais de Marx. Tradução de Carlos Nelson Coutinho. São Paulo: Livraria Editora Ciências Humanas, 1979.

PAULO NETTO, J. A construção do Projeto ÉticoPolítico do Serviço Social. In: MOTA, A. E. et al. (Orgs.). Serviço Social e Saúde: formação 
e trabalho profissional. São Paulo: OPAS, OMS, Ministério da Saúde, 2006.

PAULO NETTO, J. Capitalismo monopolista e Serviço social. São Paulo: Cortez, 1996.

Ditadura e serviço social: uma análise do serviço social no Brasil pós-64. 9. ed. São Paulo: Cortez, 2006.

SAMPAIO JR, P. de A. Desenvolvimento e neodesenvolvimentismo: tragédia e farsa. Serviço Social e Sociedade, São Paulo, n. 112, p. 673-688, out./dez. 2012.

SANTOS, J. S. Neoconservadorismo pósmoderno e Serviço social brasileiro. São Paulo: Cortez, 2007. (Coleção questões de Nossa Época).

\section{NOTAS}

1 A partir das referências de Mészáros (2002), entendemos que o controle social é uma necessidade e um fato em qualquer forma de organização social e de produção. Para o autor, a "[...] função do controle social foi alienada do corpo social e transferida para o capital, que adquiriu assim o poder de aglutinar os indivíduos num padrão hierárquico estrutural e funcional, segundo o critério de maior ou menor participacão no controle da produção e da distribuição." (MÉSZÁROS, 2002, p. 991).

2 No final do século XIX e início do século $X X$, o imperialismo europeu viu-se ameaçado pela expansão do capitalismo norte-americano. Nesse período, milhões de imigrantes vindos de regiões empobrecidas da Europa foram absorvidos pela economia norteamericana. $\mathrm{Na}$ primeira fase do desenvolvimento industrial estadunidense, a agricultura foi desenvolvida em larga escala, houve uma expansão da siderurgia e da exploração petrolífera, além do aperfeiçoamento dos transportes. Em verdade, os Estados Unidos beneficiaram-se do crescimento estimulado pela necessidade de abastecer os aliados da Primeira Guerra Mundial. Com o fim da guerra, os Estados Unidos tornam-se os maiores credores da Europa, como destaca Aquino, Lemos e Lopes (2008, p. 329): "O protetorado sobre Cuba, a Questão do Canal do Panamá e inúmeras intervenções armadas na América Latina no decorrer do século XX consolidaram a influência política e econômica dos Estados Unidos sobre esta parte do mundo: aplicou-se o Big Stick, justificado pelo corolário Roosevelt." O imperialismo norte-americano consolidou a sua expansão sobre a América Latina no período compreendido entre as duas guerras mundiais. À America Latina cabia (e ainda cabe) o papel de exportar alimentos e matérias-primas e importar bens industrializados.

3 A nova roupagem do conservadorismo insere-se no contexto de que o ethos profissional tradicional deveria ser contido, ao mesmo tempo em que deveria ser uma proposta alternativa capaz de neutralizar as novas influências que provinham das referências marxistas. Tal proposta supunha reatualizar o conservadorismo, dando a ele um caráter de uma nova proposta, que significava uma recusa aos padrões teóricometodológicos da tradição positivista. Nesse contexto, a tendência renovadora lança mão da fenomenologia como instrumento para a reelaboração teórica e prática da profissão.

\section{Cristiana Costa Lima}

Assistente Social

Doutora em Políticas Públicas pela Universidade Federal do Maranhão (UFMA)

Professora do Departamento de Serviço Social da UFMA E-mail: costalima.cristiana@gmail.com

\section{Universidade Federal do Maranhão - UFMA}

Cidade Universitária Dom Delgado

Av. dos Portugueses, n. 1966, Bacanga, São Luís/MA CEP: $65085-580$ 